\title{
Embolectomy for massive pulmonary embolism after cesarean delivery
}

\author{
Ki Hoon Ahn MD PhD, Soon-Cheol Hong MD PhD
}

$\mathrm{D}$ yspnea and hypotension developed in a 35-year-old woman about 24 hours after an apparently uncomplicated cesarean delivery at term. The patient was acutely distressed and fully conscious, with a blood pressure of $80 / 60 \mathrm{~mm} \mathrm{Hg}$, a heart rate of 148 beats/min and a respiratory rate of 36 breaths/min. Her oxygen saturation was $80 \%$ on room air. There was no evidence of active uterine bleeding. Chest computed tomography (CT) angiography showed massive bilateral pulmonary thromboembolism and right ventricular dysfunction (Appendix 1, available at www.cmaj.ca/lookup/suppl/doi:10 $.1503 / \mathrm{cmaj} .150176 /-/ D C 1)$. Emergency openlung embolectomy was performed, and large clots were removed from both lungs (Figure 1). The patient's cardiac function and heart size returned to normal, and she was discharged 15 days later.

Pregnancy has been estimated to increase the risk of venous thromboembolism by about fivefold. ${ }^{1}$ Risk factors include multiparity, obesity and cesarean delivery. The risk of venous thromboembolism is twofold higher after cesarean delivery than after vaginal delivery. ${ }^{2}$ Dyspnea, chest pain, cough and diaphoresis may be early findings of pulmonary embolism. Diagnosis of pulmonary embolism in hemodynamically unstable patients can be facilitated by echocardiography, bedside leg ultrasonography and CT pulmonary angiography. ${ }^{3,4}$ Early treatment involves low-molecularweight heparin and subsequent overlap with warfarin; unfractionated heparin may be used in patients with renal insufficiency or those who require urgent surgery. ${ }^{3}$ Thrombolysis, catheter embolectomy and open surgery are treatment options for massive pulmonary embolism (including cases in which sustained hypotension and right ventricular dysfunction are present) or for submassive pulmonary embolism (in the context of right ventricular strain and no sustained hypotension). ${ }^{5}$ For our patient, open embolectomy was selected because of the size of embolism and the patient's unstable vital signs.

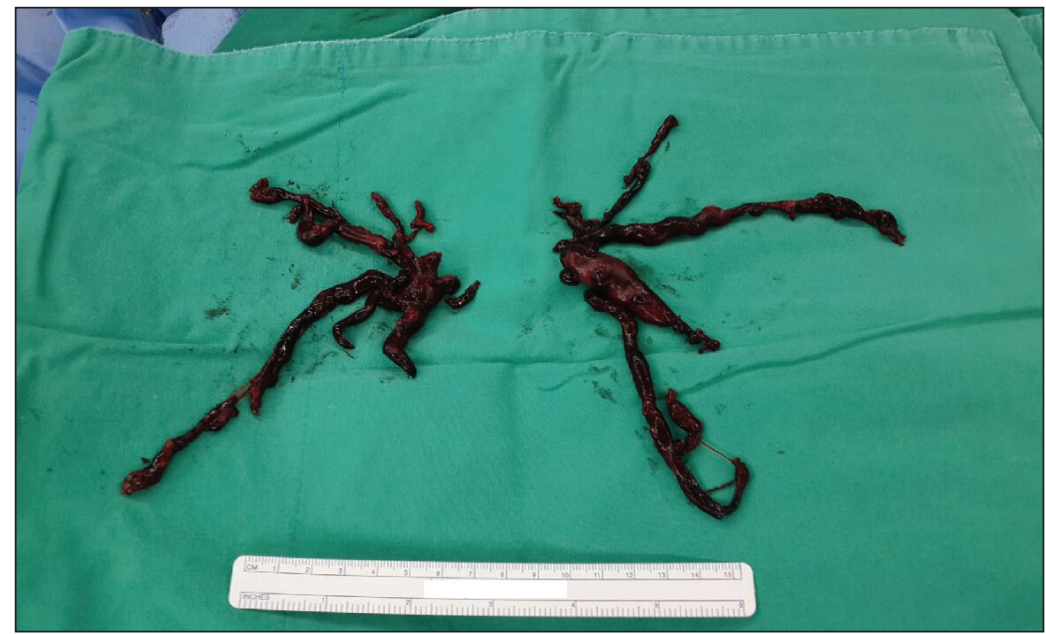

Figure 1: Massive pulmonary emboli removed from both lungs of a 35-year-old woman during emergency embolectomy 24 hours after an uncomplicated cesarean delivery.

\section{References}

1. Heit JA, Kobbervig CE, James AH, et al. Trends in the incidence of venous thromboembolism during pregnancy or postpartum: a 30-year population-based study. Ann Intern Med 2005; 143:697-706.

2. Larsen TB, Sørensen HT, Gislum M, et al. Maternal smoking, obesity, and risk of venous thromboembolism during pregnancy and the puerperium: a population-based nested case-control study. Thromb Res 2007;120:505-9.

3. Bourjeily G, Paidas M, Khalil H, et al. Pulmonary embolism in pregnancy. Lancet 2010;375:500-12.

4. Agnelli G, Becattini C. Acute pulmonary embolism. $N$ Engl J Med 2010;363:266-74.

5. Jaff MR, McMurtry MS, Archer SL, et al. Management of massive and submassive pulmonary embolism, iliofemoral deep vein thrombosis, and chronic thromboembolic pulmonary hypertension: a scientific statement from the American Heart Association. Circulation 2011;123:1788-830.

Clinical images are chosen because they are particularly intriguing, classic or dramatic. Submissions of clear, appropriately labelled high-resolution images must be accompanied by a figure caption and the patient's written consent for publication. A brief explanation (250 words maximum) of the educational significance of the images with minimal references is required.
Competing interests: None declared.

This article has been peer reviewed.

The authors have obtained patient consent.

Affiliation: Department of Korea University Medical Center, Seoul, South Korea

Acknowledgement: The authors acknowledge Dr. Jae Seung Jung, professor in the Department of Thoracic and

Cardiovascular Surgery,

for his outstanding surgical knowledge and skills in the care of this patient.

Correspondence to: Soon-Cheol Hong, novak082@naver.com

CMAJ 2016. DOI:10.1503 /cmaj.150176 Obstetrics and Gynecology, 